\section{Estudo \\ CoDebate}

em Cestão

Plamejamento
Revista Estudo \& Debate, Lajeado, v. 28, n. 1, 2021. ISSN 1983-036X

DOI: http://dx.doi.org/10.22410/issn.1983-036X.v28i1a2021.2604

\title{
UMA COMPARAÇÃO DAS POLÍTICAS INDUSTRIAIS BRASILEIRAS A PARTIR DE MATRIZES DE POLÍTICAS INDUSTRIAIS
}

\author{
Rodrigo Milano de Lucena ${ }^{1}$, Jorge Nogueira Paiva de Britto ${ }^{2}$
}

\begin{abstract}
Resumo: As discussóes sobre definiçôes de política industrial sempre estiveram presentes nos estudos econômicos e focam principalmente no modo e tamanho da intervenção do Estado neste processo. No Brasil, o caso não é diferente e, apesar de políticas industriais estarem presentes na economia brasileira desde a década de 1930, os esforços não são contínuos. Porém, a partir dos anos 2000, houve três esforços brasileiros para a criaçáo de políticas industriais que gerassem competitividade internacional: a PITCE, a PDP e o PBM. Diante disso, o objetivo deste artigo é ilustrar e comparar estes três esforços de política industrial brasileiros com relação aos níveis de intervenção e fatores socioeconômicos atingidos. Para isso, foi utilizada a Matriz de Política Industrial criada por O'Sullivan et al. (2013), a fim de sistematizar os principais pontos das políticas com relaçáo aos agentes alvo e o papel do Estado nesta coordenaçáo. As conclusóes dos autores foram que, durante a vigência das três políticas industriais adotadas, houve crescimento do papel do Estado na articulação e fomento do desenvolvimento industrial brasileiro. As políticas apresentaram certo grau de coordenação e evolução durante os anos. Porém, como característica da economia brasileira, em períodos de crise, a política industrial é interrompida e novamente isto se verificou com o cenário econômico atual.
\end{abstract}

Palavras-chave: Avaliação de Políticas Públicas; Política Industrial; Economia Brasileira.

\section{BRAZILIAN INDUSTRIAL POLICIES COMPARISON FROM INDUSTRIAL POLICY MATRICES}

\begin{abstract}
The discussions on industrial policies definitions have always been present in economic studies and focus mainly on the mode and size of state intervention in this process. In Brazil, the case is not different. Although industrial policies have been present in the Brazilian economy since the 1930s, the efforts are not continuous. However, since the 2000s there have been three Brazilian efforts to create industrial policies that generate international competitiveness, PITCE, PDP and PBM. Therefore, the aim of this paper is to illustrate and compare these three Brazilian industrial policy efforts with respect to intervention levels and socioeconomic factors. For this, It was used the Industrial Policy Matrix created by O'Sullivan et al. (2013), in order to systematize the main points of the policies regarding target agents, and the role of the State in this coordination. The authors' conclusions were that during the validity of the three industrial policies adopted, there was an
\end{abstract}

1 Doutorando em Economia pelo PPGE/UFF e professor Assistente da Universidade Federal de Rondonópolis (UFR).

2 Doutor em Economia pelo IE/UFRJ e Professor Associado do PPGE/UFF. 
increase in the role of the State in articulating and fostering Brazilian industrial development. Policies have shown some degree of coordination and evolution over the years. However, as a characteristic of the Brazilian economy, in periods of crisis, industrial policy is interrupted and again this has been tested with the current economic scenario.

Keywords: Public Policy Evaluation; Industrial Policy; Brazilian economy.

\section{1) Introduçáo}

Política industrial vem sendo alvo de discussão na agenda de governos ao redor do mundo há pelo menos dois séculos (Andreoni e Chang, 2018). Devido ao grande intervalo de tempo, as discussóes sobre como implementar políticas industriais e qual o papel do Estado nesta implementação também evoluíram bastante e foram alvo de diversas discussōes teóricas (CHANG, 1994; CIMOLI et al., 2007).

Discussóes mais recentes destacam o papel sistêmico da política industrial para o desenvolvimento de um ambiente inovativo e que busque competitividade no cenário internacional, ocupando posiçóes estratégicas nas Cadeias Globais de Valor.

No Brasil, o discurso sobre a definição e implementação de políticas industriais na agenda de governo é marcado por sucessivas mudanças no decorrer do tempo, já indicando que nunca houve um esforço coordenado e de longo prazo para o desenvolvimento industrial. Porém, recentemente, a política industrial voltou a ser pauta estratégica nos governos brasileiros. Mais especificamente, a partir dos anos 2000, três grandes políticas foram criadas a fim de gerar o desenvolvimento industrial e ganhos de competitividade: PITCE (Política Industrial, Tecnológica e de Comércio Exterior, criada em 2004); PDP (Política de Desenvolvimento Produtivo, criada em 2008) e o PBM (Plano Brasil Maior, criado em 2011). Estas políticas perpassaram trocas de governos e crises econômicas internacionais, o que fez cada uma delas ser elaborada sob um contexto político e socioeconômico diferente e possuírem aspectos positivos e negativos.

Diante disso, o presente trabalho busca ilustrar e comparar estes três esforços de política industrial com relação aos níveis de intervenção e fatores socioeconômicos atingidos. Esta investigação torna-se relevante visto que, como historicamente não há um planejamento de longo prazo para o desenvolvimento da indústria brasileira, uma possível coordenação entre as três políticas adotadas ao longo dos últimos anos pode indicar o início do esforço de uma política nacional de desenvolvimento pautada na política industrial e de inovação.

Este trabalho está dividido em quatro seçôes, além desta introdução e da conclusão. Inicia-se com uma breve revisão de literatura sobre conceitos de política industrial e o papel do Estado. Posteriormente, é apresentado um histórico destas políticas no país, junto com uma caracterização das políticas industriais brasileiras que serão objeto da pesquisa. O tópico seguinte é composto pela apresentação da Matriz de Política Industrial que foi utilizada como referência para a análise, seguida dos resultados e discussóes e, por fim, as principais conclusóes do trabalho. 


\section{2) Política Industrial e o Papel do Estado}

Segundo Chang (1994), as primeiras discussóes sobre política industrial já dissertavam sobre a necessidade da intervenção estatal na economia. Primeiramente, a ação de política industrial podia ser resumida apenas na correçáo de falhas de mercado, tais como carteis, trustes e grandes fusóes e aquisiçóes.

Discussões mais recentes ampliam a atuação de política industrial para ações mais sistêmicas e coordenadas com outras políticas econômicas. De acordo com Johnson (1984), política industrial é definida como um conjunto de açóes governamentais que desenvolvem a indústria para a manutenção da competitividade internacional.

Complementando a ideia, Cimoli et al. (2007) discutem a proposição de política industrial em coevolução com as instituiçôes, afirmando que ela vai muito além do que a mera determinação de diretrizes e programas específicos para o setor industrial, no sentido de determinar a fronteira entre as instituiçóes mercantis (como uma indústria de medicamentos) e não mercantis (como universidades e centros de pesquisa), isto é, até onde as instituiçóes mercantis podem atuar e até onde vai o papel das instituições não mercantis na constituição do tecido socioeconômico. Portanto, a política industrial aborda muito mais do que a indústria apenas. Suas ações devem extrapolar os limites da produção para garantir e coordenar os esforços que objetivam o desenvolvimento.

$\mathrm{O}$ conceito de política industrial se modificou bastante no decorrer do tempo e esta alteração vem acontecendo principalmente por conta de respostas às crises econômicas, novos padróes de concorrência, crescimento das cadeias globais de valor, redes de marketing e outros aspectos da globalização (HAQUE, 2017; AGHION; BOULANGER; COHEN, 2011). Portanto, política industrial não pode mais ser pensada como açóes restritas a um financiamento específico ou apenas a promoção de certas atividades. A realidade econômica do processo de acumulação capitalista atual exige esforços mais abrangentes e sistêmicos quando se trata de política industrial, principalmente devido ao rápido processo de globalização mundial (CASSIOLATO E LASTRES, 1999).

A fim de exemplificar o quão abrangente pode ser a política industrial, Suzigan e Vilella (1997) elencam algumas políticas auxiliares à política industrial e seus instrumentos, evidenciando o quão sistêmica precisa ser esta política para gerar o desenvolvimento industrial: a) política comercial, utilizando de tarifas, barreiras não tarifárias, incentivos à exportação, subsídios produtivos, financiamento à exportação e garantia de crédito, financiamento à importação; b) financiamento instrumentado por crédito para investimento de longo prazo, financiamento para o desenvolvimento de P\&D e de tecnologia; c) políticas de promoção, tais como incentivos ao desenvolvimento regional e suporte a micro e pequenas empresas; d) políticas de regulação, incluindo legislação antitruste, legislação para os direitos de propriedade, regulação do investimento externo direto, regulação da transferência de tecnologia, regulação do mercado de trabalho, regulação de concessão de serviços públicos, legislação ambiental, dentre outros.

Ainda de acordo com Suzigan e Vilella (1997), as políticas industriais devem ter o objetivo gerar ganhos de competitividade a partir da promoção e da solidificação da infraestrutura física (como a geração e distribuição de energia, melhoramento do sistema 
de transportes, portos, telecomunicaçóes), da infraestrutura de P\&D (universidades e institutos de pesquisa científica e tecnológica) e da educação e qualificação de recursos humanos. Haque (2007) acrescenta que todos esses requisitos precisam estar atrelados ao aumento da produtividade.

Com relação ao processo inovativo, a política industrial também evoluiu. No período entre o fim da Guerra Fria e os anos 1980, o processo inovativo era influenciado pelo Modelo Linear de Inovação, em que se parte da pesquisa básica, passando pela criação de um produto e, por último, pelo lançamento da tecnologia no mercado, completando a linha da inovação. Porém, a política de industrial atual, por ter o caráter sistêmico, fomenta o processo inovativo através do Sistema Nacional de Inovação, com ações de diversos agentes, coordenados pelas açóes do Estado, de um modo complexo, não linear (Barbosa, Bagattolli e Invernizzi, 2018).

No mundo, há poucos casos de sucesso em que o governo não atuou ativamente para a promoção da indústria. Nelson (2006) justifica a intervenção estatal nesta coordenação entre os agentes pelo simples fato de que o retorno do investimento na inovação pelas firmas não é garantido, uma vez que o conhecimento pode se tornar um bem público, fazendo com que o mercado não oferte uma quantidade suficiente de inovação socialmente desejada.

Especificamente para os países em desenvolvimento, a CEPAL (Comissão Econômica para a América Latina e Caribe) desenvolveu uma doutrina da industrialização como forma de superar barreiras históricas ao crescimento da região a partir da década de 1950, sempre com o papel do Estado sendo fundamental neste processo (Laplane, 2015).

Porém, as políticas dos Estados mais desenvolvidos, se replicadas aos Estados em desenvolvimento, dificilmente trarão o mesmo êxito. Isto acontece porque a replicação de política bem-sucedidas não tem o mesmo efeito por não considerar a realidade econômica diversa das regióes mais atrasadas. Dar ênfase para a economia local, por exemplo, é um papel de suma importância para as economias em desenvolvimento (HAQUE, 2007).

Mas variáveis-chave podem ser encontradas em diversas políticas industriais de sucesso tais como incentivo a pesquisa e desenvolvimento, formação e qualificação da mão de obra, financiamento para setores-chave, etc. Portanto, as políticas industriais, mesmo em países em desenvolvimento, com suas restriçóes e peculiaridades, devem levar em consideração estas variáveis principais, assim como o tamanho e o papel do Estado na articulação entre os agentes, além das características econômicas locais.

\section{3) Políticas Industriais Brasileiras}

No Brasil, o desenvolvimento de políticas voltadas para o desenvolvimento industrial não é novo, tendo o governo historicamente incentivado a indústria nacional de diversas formas. Pode-se dizer que uma política intencional efetiva com investimentos públicos significativos nos setores industriais iniciou-se no período desenvolvimentista de JK (anos 60) (Vilella, 2005) e continuou no segundo Plano Nacional de Desenvolvimento no governo do general Ernesto Geisel (Suzigan e Vilella, 1997). Autores como Bielschowsky (2014) afirmam que a industrialização brasileira ocorreu ainda antes de forma acelerada entre 1930 a 1980, ampliando a margem temporal do desenvolvimento industrial brasileiro. 
Bielschowsky (2014) afirma ainda que, a partir de 1950, o desenvolvimento industrial foi conduzido pelo Estado e acompanhado pela hegemonia ideológica desenvolvimentista.

Este processo se iniciou a partir do contexto de crise econômica internacional provocado pela crise de 1929, onde os países latino-americanos tiveram perdas vertiginosas de suas exportaçóes baseadas em produtos primários. Com isso, a capacidade de importação de bens de consumo também foi impactada, o que foi, aos poucos, sendo substituída pela produção interna e que posteriormente foi denominada de política de substituição de importaçóes, bastante relevante para o processo de desenvolvimento brasileiro. Neste contexto, as importaçóes agora tinham a função de diversificação da estrutura produtiva, mediante entrada de equipamentos e bens intermediários (TAVARES, 2000). Este Modelo conseguiu perdurar até meados da década de 1970, onde houve um grande avanço no processo de industrialização brasileiro com o desenvolvimento de setores importantes como agoindústria moderna, mineração, metalurgia dos minerais não-ferrosos, petroquímica, bens de capital e até do setor eletrônico (CANO E SILVA, 2010).

Entre as décadas de 1970 e 1980, o Brasil passou pela situação denominada "doença soviética”, com a participação da indústria no PIB muito superior à média internacional. Entre 1988 e 1993, houve um período de correção desta trajetória, com a participação da indústria no PIB diminuindo seu peso desde então (Sarti e Hiratuka, 2015). Muito desse resultado se deu principalmente pela crise da dívida de 1980 e pelos programas de estabilização enfrentados pela economia brasileira no início da década de 1990, que deixavam para o segundo plano projetos de desenvolvimento industrial (CANO E SILVA, 2010).

Porém, os resultados dessas políticas aplicadas até os anos 1980 não prepararam o Brasil estruturalmente, fazendo com que os investimentos baseados em expectativas de continuidade das condiçóes favoráveis do mercado internacional deixassem o país vulnerável ao mercado externo, assim como aconteceu com diversos países da América Latina, principalmente a partir da moratória mexicana em 1982. O resultado disso foi o atraso do governo brasileiro no que se refere a um plano industrial de desenvolvimento.

Importante destacar que, até os anos 1980, o Estado teve um papel relevante para o desenvolvimento industrial brasileiro. Pode-se inferir que, historicamente, a indústria brasileira não consegue se articular de maneira independente, no sentido de promover o desenvolvimento industrial e ganhar competitividade internacional.

Assim, esforços na tentativa de se realizar políticas industriais começaram a ser repensadas em meados da década de 1990, com o controle da crise inflacionária que se arrastou durante toda a década de 1980 . Todo esse cenário corrobora com a ideia de Cassiolato, Szapiro e Vargas (2016), segundo a qual essa lacuna temporal na política industrial e de inovaçáo mostra a falta de capacidade de planejamento de longo prazo do país para o setor.

Os primeiros esforços brasileiros no sentido da criação de um sistema nacional de inovação datam da década de 1990, porém este movimento se realizou mais intensamente a partir dos anos 2000 com a compreensão por parte do governo de que a inovação é um elemento-chave para o crescimento da competitividade, tanto industrial quanto nacional, 
principalmente com a criação da Política Industrial, Tecnológica e de Comércio Exterior (PITCE), associando política industrial, inovação e gestão da tecnologia a fim de obter ganhos de competitividade (Chiarini e Vieira, 2011).

Basicamente, a partir de 2004, o Brasil conseguiu reunir esforços no sentido de estrutrurar políticas públicas voltadas ao desenvolvimento industrial, à ciência e tecnologia e à inovação. A partir dos anos 2000, foram criadas três grandes políticas, que englobam uma série de medidas e programas, centradas em fortalecer o desenvolvimento produtivo brasileiro: a PITCE (lançada em 2004), a PDP (Política de Desenvolvimento Produtivo, lançada em 2008) e o PBM (Plano Brasil Maior, lançado em 2011 sob o lema "inovar para competir"). A partir disso, elenca-se as principais medidas de cada política a fim de caracterizá-las dentro do contexto em que cada uma se coloca e apresentar os principais objetivos determinados pelos policymakers.

\section{A PITCE}

Como já mencionado, esta primeira política voltou a colocar a política industrial dentro da agenda de governo. Sem grandes mudanças econômicas, o governo Lula voltou a considerar a indústria como motor do crescimento e do desenvolvimento econômico sem alterar a política macroeconômica que vinha sendo feita desde 1999 (CANO E SILVA, 2010).

A PITCE foi formulada através de 57 medidas, distribuídas em 11 programas, coordenadas com diversos agentes e focadas em inovação como o promotor do desenvolvimento industrial. Os principais objetivos da política eram o aumento da eficiência econômica e do desenvolvimento e difusão de tecnologias com maior potencial de indução do nível de atividade e de competição no comércio internacional. Mesmo propondo algumas linhas horizontais de atuação, como inserção externa, modernização industrial e aumento da capacidade produtiva, o foco da política era no desenvolvimento de alguns setores estratégicos (semicondutores, software, bens de capital e fármacos) e de atividades portadoras de futuro (biotecnologia, nanotecnologia, biomassa/energias renováveis) (CANO E SILVA, 2010; ALMEIDA, 2011; FERRAZ, MARQUES E ALVES JR, 2015).

As opçóes estratégicas, de acordo com a PITCE, apresentam uma nítida relação com as políticas de infraestrutura (energia, logística e saneamento, e telecomunicaçóes, respectivamente) e isso justifica a escolha desses setores como prioritários na referida política.

Uma das medidas dentro da PITCE foi a promulgação da Lei da Inovação, cujo objetivo é estimular a inovação através da subvenção econômica e da eliminação de gargalos instituicionais entre parcerias público-privadas, o que aproximou as intituiçóes de pesquisa da indústria. Outro alvo da Lei é a desburocratização do processo de transferência de tecnologia, ampliando a aproximação dos esforços de ciência e tecnologia dos institutos de pesquisa com relação à necessidade do ambiente produtivo. Ou seja, mesmo não estando explicitamente nos objetivos gerais da política, a PITCE fomentou a formação do Sistema Nacional de Inovação brasileiro e permitiu a troca de conhecimento entre setores mercantis e não mercantis. Ainda no âmbito da Lei da Inovação, ela cria a possibilidade de compras tecnológicas por parte do Estado. 
Dentre outras medidas legais da PITCE, tem-se a Lei do Bem e a Lei da Informática. A Lei do Bem incentivou o aumento do investimento em P\&D por parte das grandes empresas empresas, diminuindo os custos e riscos. A Lei da Informática prevê benefícios fiscais a empresas do setor que investem em $\mathrm{P} \& \mathrm{D}$, evidenciando que as medidas políticas colocam como central a inovaçáo no processo de desenvolvimento industrial brasileiro (SALERNO e DAHER, 2006; AVELLAR E BOTELHO, 2016).

Alguns autores, como Salerno e Daher (2006), colocam também a Lei de Biossegurança como um marco dentro das políticas industriais e de inovação, por viabilizarem pesquisa e desenvolvimento com organismos geneticamente modificados e com células-tronco, além de focar na inibição da biopirataria.

Com relação ao financiamento, o BNDES e a FINEP tiveram papeis fundamentais para o andamento da política, com a reentrada nos financiamentos à inovação. A FINEP possui vasta experiência no financiamento para a inovação e que novamente ganhou força a partir dos anos 2000, com a captação de recursos oriundos dos Fundos Setoriais e que, mesmo com seu funcionamento sendo alterado diante de alteraçóes do quadro político, se consolidou como a principal organização de fomento ao desenvolvimento econômico brasileiro (COSTA, 2013)

Diversas medidas foram tomadas para que o BNDES auxiliasse no processo de desenvolvimento industrial, como os programas setoriais de apoio (Prosoft, Profarma, Proengenharia, Funtec) e a participaçáo no capital de empresas inovadoras, diretamente ou via fundos, como o Criatec (Ferraz, Marques e Alves Jr, 2015).

O BNDES exerceu importante função tanto na formulação de programas que auxiliaram a PITCE, quanto no financiamento dos setores elencados como prioritários na política. Seu papel se manteve fundamental durante todo o andamento da política, trazendo grandes resultados para a economia brasileira. Juntamente com a FINEP, o BNDES também utilizou de medidas que auxiliaram o financiamento de pequenas e médias empresas.

Com relação à formação de mão de obra qualificada, a CAPES e o MEC criaram novos critérios para a distribuição e ampliação de bolsas de mestrado e doutorado do Programa de Demanda Social, direcionando tais auxílios para áreas prioritárias na PITCE, recebendo bolsas específicas, refletindo diretamente na ampliação da formação de doutores no Brasil, principalmente na grande área de engenharias (ABDI, 2007).

Devido à complexidade da política, foi necessário garantir mecanismos de coordenação exercidos por grupos de trabalho de âmbito interministerial, cujo objetivo era monitorar mercados, empresas, cadeias, arranjos produtivos, redes de empresas e firmas no cumprimento dos objetivos firmados dentro dos programas estabelecidos (ABDI, 2007). Para Salerno e Daher (2006), o Estado brasileiro pecou na abrangência das formulaçóes de política industrial e, por isso, vários instrumentos do desenvolvimento produtivo ficaram sob responsabilidade de várias pastas (tais como Ministérios, a FINEP, dentre outros), o que torna necessária a coordenação e se configura em custos para a execução e o monitoramento. 


\section{A PDP}

Esta Política foi criada no segundo governo Lula e tinha como meta uma continuidade e ampliação das medidas da PITCE, porém de forma bem mais estruturada (Castelli, 2017). $\mathrm{Na}$ PDP, foram inseridas medidas tributárias/fiscais, de financiamento, poder de compra por parte do governo, aprimoramento jurídico, regulação e apoio técnico. $\mathrm{O}$ objetivo central da política era a sustentaçáo do desenvolvimento produtivo e seus pilares eram o investimento e a inovação, trazendo geração de empregos e aumento da competitividade internacional. Como principais desafios, a política traz a preservação de resultados favoráveis no balanço de pagamentos, ampliaçáo da capacidade de produção e de serviços interna, e o desenvolvimento das pequenas e médias empresas.

A política realizaou a desoneração de diversos setores produtivos, numa reúncia fiscal de cerca de R \$ 21 bilhóes entre 2008 e 2011 . Apesar de não ter havido coordenação entre as políticas macroeconômicas e a política industrial no Brasil neste período, foi o cenário macroeconômico que permitiu este avanço: inflação estável, reservas internacionais elevadas, redução do desemprego, aumento do emprego formal e da massa salarial, mercado de crédito e microcrédito em expansão e aumento do grau de investimento (CASTELLI, 2017).

Mesmo com a política industrial inserida fortemente na agenda de governo, a PITCE não foi capaz de mudar drasticamente o ambiente institucional, permanecendo a responsabilidade de implementação da PDP distribuída por várias pastas dos Ministérios, centralizadas num Conselho Gestor composto por representantes dos ministérios da Casa Civil, Fazenda, Planejamento, Ciência e Tecnologia e Educação. Porém, há autores que relatam aspectos positivos da mudança institucional da política. Ferraz, Marques e Alves Jr, (2015), por exemplo, colocam a governança da política como próxima do Plano de Metas, criando Comitês Executivos para gerir os diversos programas e uma Secretaria Executiva para a coordenação dos conselhos e dos programas, dando suporte ao MDIC.

Contrastando com o que tinha sido proposto pela PITCE, o caráter da PDP era mais horizontal e comtemplava 24 setores da economia, motivo pelo qual foi muito elogiada por diversos agentes econômicos, já que nela agora se contemplava os setores intensivos em mão de obra da indústria brasileira. A seguir se apresentam os setores industriais alvo da política divididos por grupos de programas:

\begin{tabular}{c|l}
\hline Grupo de programa & \multicolumn{1}{c}{ Setores } \\
\hline $\begin{array}{c}\text { Programas para } \\
\text { consolidar e expandir a } \\
\text { liderança }\end{array}$ & $\begin{array}{l}\text { Aeronáutico; petróleo, gás e petroquímica; bioetanol; mineração; } \\
\text { celulose e papel; siderurgia; e carnes. }\end{array}$ \\
\hline $\begin{array}{c}\text { Programas para } \\
\text { fortalecer a } \\
\text { competitividade }\end{array}$ & $\begin{array}{l}\text { Complexo automotivo; bens de capital; indústria naval e cabotagem; } \\
\text { têxtil e confecçóes; couro, calçados e artefatos; madeira e móveis; } \\
\text { agroindústrias; construção civil; complexo de serviços; higiene, } \\
\text { perfumaria e cosméticos; e plásticos. }\end{array}$ \\
\hline $\begin{array}{c}\text { Programas } \\
\text { mobilizadores em áreas } \\
\text { estratégicas }\end{array}$ & $\begin{array}{l}\text { Complexo industrial da saúde; tecnologias da informação e comunicação; } \\
\text { energia nuclear; nanotecnologia; biotecnologia; e complexo industrial } \\
\text { da defesa. }\end{array}$ \\
\hline
\end{tabular}

Fonte: elaborado pelo autor baseado em (BRASIL, 2010 e CANO E SILVA, 2010). 
Além destes 3 grupos de programas, há ainda um grupo chamado de Destaques Estratégicos, considerado como a grande mudança da política industrial brasileira juntamente com a ampliaçáo dos setores trabalhados. Este grupo contém os programas assim denominados: Promoção das exportaçóes; Regionalização; Micro e pequenas empresas; Produção sustentável; Integração com a África; Integração produtiva com a América Latina e Caribe.

Outra ação importante da PDP, além de elencar mais setores que a PITCE como estratégicos na agenda, foi escolher empresas dentro destes setores e colocar como objetivo um planejamento de inseri-las entre as cinco maiores do mundo (Calzolaio, 2015).

Como já iniciado pela PITCE, o BNDES também foi um agente importante para a implementação da política, mas seu papel se tornou central na implementação desta referida política. As principais medidas do Banco foram a ampliação maciça do montante destinados a financiamentos para os setores da indústria e de serviços. O BNDES, além de cobrar taxas especiais para empresas que investissem em $P \& D$, ampliou prazos de financiamento e reduziu entre $20 \%$ a $40 \%$ o spread básico em suas linhas de financiamento, principalmente nas linhas de comercialização de bens de capital (CANO E SILVA, 2010).

Outro papel importante do BNDES dentro da PDP foi o de membro da Secretaria Executiva, atuando mais de perto nas decisões sobre prioridades de financiamento de investimento, exportação e internacionalização de produtos brasileiros (FERRAZ, MARQUES E ALVES JR, 2015).

\section{O PBM}

O denominado Plano Brasil Maior foi uma política industrial, tecnológica e de comércio exterior do governo federal, elaborada já no primeiro mandato da presidenta Dilma Rousseff e buscava manter a estratégia desenvolvimentista do governo anterior, principalmente do segundo mandato do Governo Lula. Com o lema "Inovar para competir, competir para crescer", esta política era bem mais abrangente do que todas as anteriores por englobar, além da indústria, incentivos ao comércio exterior e ao setor de comércio e serviços, tanto no mercado interno quanto no externo, com metas estabelecidas para o ano de 2014 (ABDI, 2013).

O Plano também foca na construção de um Sistema Nacional de Inovação quando estabelece "aproveitar competências presentes nas empresas, na academia e na sociedade, construindo um país mais próspero e inclusivo" (ABDI, 2018).

As questóes sistêmicas voltadas para a eliminação de entraves e aumento da produtividade da indústria como um todo também são abordadas, mas sem descartar a dinâmica estratégica setorial, que foi ordenada em cinco blocos e orientam a formulação e implementação de programas e projetos de vários agentes coordenados e alinhados com os objetivos do referido Plano.

O conjunto de medidas do Plano pode ser organizado em conjuntos de açóes com o objetivo de: a) reduzir dos custos dos fatores de produção e oferta de crédito para investimentos; $\mathrm{b}$ ) desenvolver de cadeias produtivas, indução do desenvolvimento tecnológico e qualificaçáo profissional; c) promover das exportaçôes e defesa do mercado interno. Todos 
os intrumentos para se atingir tais objetivos são operados de maneira articulada com outras iniciativas, como a Estratégia Nacional de Ciência, Tecnologia e Inovação (ENCTI), o Programa de Aceleração do Crescimento (PAC), o Programa de Investimento em Logística, o Minha Casa Minha Vida, o Brasil Sem Miséria, a Estratégia Nacional de Defesa, e os programas setoriais de saúde, educação, meio ambiente e desenvolvimento regional e agrário (ABDI, 2014).

A gestão do Plano foi assim formada, de acordo com Toni (2015 p. 76):

a) 19 Comitês Executivos com recorte setorial; b) 9 Coordenações Sistêmicas, responsáveis por temas transversais como comércio exterior, relaçóes do trabalho e desenvolvimento regional; c) um Grupo Executivo, com representantes de ministérios e agências relevantes, do qual o BNDES faz parte; d) um Comitê Gestor interministerial; além do Conselho Nacional de Desenvolvimento Industrial (CNDI), órgáo tripartite de aconselhamento da política existente desde a PITCE.

Nas palavras de Schapiro, (2013) no que toca ao desenho institucional e à burocracia, tem-se que a governança do PBM, assim como nas políticas anteriores estudadas, não é centralizada, funcionando como um hub institucional das diferentes agências e orgãos de fomento, contando ainda com uma burocracia ad hoc, gerando debilidades de coordenação e de implementação, trazendo, principalmente, problemas na tomada de decisão.

As 69 medidas adotadas pela política se centraram principalmente no Ministério da Fazenda, o que pode ter se refletido em desalinhamentos com a proposta de desenvolvimento da ciência e tecnologia no país. Mesmo com a falta de alinhamento entre os diversos atores da política, a ENCTI teve sua elaboração sob responsabilidade do MCTI e colocou como objetivo central a revolução educacional e sua incorporação sistemática ao processo produtivo.

Como principal instrumento das políticas industriais anteriores, o BNDES ganhou força como fonte de financiamento e apoio à inovação das empresas brasileiras. Especificamente para o PBM, o BNDES revisou o PSI, criou o subprograma de Projetos Transformadores. $\mathrm{O}$ montante de financiamentos focou principalmente os setores estratégicos elencados pelo plano, que somou cerca de $80 \%$ dos recursos destinados à indústria, com destaque para os setores de mecânica, eletrônica e saúde. As MPEs também foram grandes beneficiadas pelo BNDES nos anos vigentes do Plano (TONI, 2015).

Ainda que o PBM apresentasse noçóes de interrelacionamentos entre os agentes para um esforço de mudança estrutural da indústria brasileira a partir da inovação, este não foi eficiente no que se refere ao apoio a setores estratégicos, elencando principalmente setores intensivos em trabalho como alvo da política, o que leva mais à defesa da estrutura produtiva presente do que a transforma e aproxima da fronteira tecnológica (Castelli, 2017).

Como forma de internacionalização da educação superior, foi criado em 2011 no Brasil o Ciências Sem Fronteiras, que, conforme aos objetivos do PBM, utilizou a mobilidade internacional de alunos de graduação e pós-graduação com o intuito de promover a consolidação, expansão e a internacionalização da ciência, tecnologia e inovação e da competitividade brasileira por meio do intercâmbio e da mobilidade internacional. 
Foram elencadas 18 principais áreas contempladas pelo programa, a maioria delas compatível com as áreas da PDP, evidenciando que os policymakers estavam alinhados na transição dos programas.

Vale ressaltar que, a partir de 2015, novamente a política industrial deixou de ser prioridade na agenda da política econômica nacional por diversos fatores tais como a crise econômica enfrentada pelo país, o conturbado cenário político e o cunho ideológico liberal do governo eleito. Conforme apresentado por Castelli (2017, p. 199):

\begin{abstract}
Ademais, um eterno entrave da política de inovação brasileira se manteve: a incompatibilidade entre a política instrumental macroeconômica (o tripé) e a política visando o gap tecnológico entre o Brasil e os demais países desenvolvidos. Afora os desdobramentos da Grécia e da zona do Euro que aumentaram ainda mais a instabilidade macroeconômica, reduzindo a margem de atuação do Estado brasileiro para dar continuidade a este tipo de política. Em situação de adversidade, a política de inovação é deixada de lado.
\end{abstract}

Isto evidencia que, apesar de aproximadamente dez anos de inclusão da política industrial na agenda de governo, ela passa por mais um ciclo e é negligenciada em dentrimento de outras medidas.

\title{
4) A Matriz de Política Industrial
}

A fim de sistematizar os principais aspectos e objetivos das políticas apresentadas, os autores optaram por apresentá-las cada uma na Matriz de Política Industrial. A referida matriz foi desenvolvida por O'Sullivan et al. (2013) para demonstrar as principais características das políticas industriais de alguns países da OECD. A principal contribuição desta matriz é a superação de algumas limitaçóes com relação as taxonomias disponíveis, tais como Pavitt (1984) na generalização do comportamento de setores industriais; Malerba e Orsenigo (1994) na transversalidade de classes tecnológicas entre países, pois não considera países em desenvolvimento; Hatzichronoglou (1997); Unctad (2002) e Lall (2000) já que não capturam as mudanças políticas ao longo do tempo.

Para caracterizar as políticas industriais com a matriz, deve-se levar em conta as mudanças pretendidas pela política e o conjunto de medidas adotadas por cada uma delas. Basicamente, a Matriz de Política Industrial trabalha, no eixo vertical, com os níveis de intervenção que a política adotada pelo país possui, classificadas como níveis de firma industrial, setor industrial, atividades intersetoriais e quadro macroeconômico, em resumo, neste eixo é avaliada a abrangência da política industrial e onde ela atua diretamente (O'Sullivan et al., 2013).

Estas medidas foram distinguidas, no eixo horizontal, de acordo com o "fator de entrada" sobre o qual as políticas atuam. São esses fatores: o conhecimento (em particular $\mathrm{P} \& \mathrm{D}$, principalmente aquele voltado para a aplicação na indústria); a força de trabalho (incluindo desde organizaçóes que auxiliam pequenas a adotarem tecnologia até a programas de formação e qualificação de mão de obra, a exemplo do Instituto Fraunhofer na Alemanha, e o SEBRAE no Brasil); capacidade de produção (disponibilidade e capacidade de usar e organizar as máquinas e equipamentos disponíveis); recursos e infraestrutura (que incluem orientações a utilização mais racional e sustentável de recursos naturais bem como formas 
de produção mais limpas e direcionamento de parques industriais baseados em fontes de energias limpas); e o capital financeiro (principalmente estratégias de acesso das empresas ao capital, principalmente as empresas de pequeno porte). O sucesso da indústria depende diretamente de sua capacidade de interagir com mercados globais e redes de cooperaçáo e conhecimento, onde a matriz sugere uma categoria adicional de medidas relacionadas a sistemas e mercados globais de manufatura.

Portanto, uma política industrial pode ser ilustrada, segundo esta taxonomia, mapeando as principais mudanças pretendidas no ambiente industrial e o conjunto de medidas e programas associados a cada um dos "fatores de entrada". A Matriz permite comparar: a) as agendas das políticas e as mudanças pretendidas; b) algumas variaçóes de medidas políticas destinadas a mudar os fatores na indústria nacional; c) o grau em que estas medidas se concentram em setores específicos, em atividades intersetoriais ou em condiçóes econômicas mais amplas; d) até que ponto as medidas propostas são coordenadas no âmbito de estratégias factíveis.

No caso específico deste trabalho, foi feita uma adaptação da matriz já que, pela característica brasileira de uma economia em desenvolvimento, tanto a localizaçáo de sua indústria quanto os esforços de política industriais ainda não foram relevantes para a incorporação desta nas cadeias globais de valor da mesma forma que os países desenvolvidos. Por isso, o trabalho atual não utilizou a coluna "Sistemas de manufatura global e mercados", por entender que essa discussão deve ser retomada em trabalhos posteriores.

Figura 1: exemplo de uma matriz de política industrial de O`Sullivan et al. (2013)

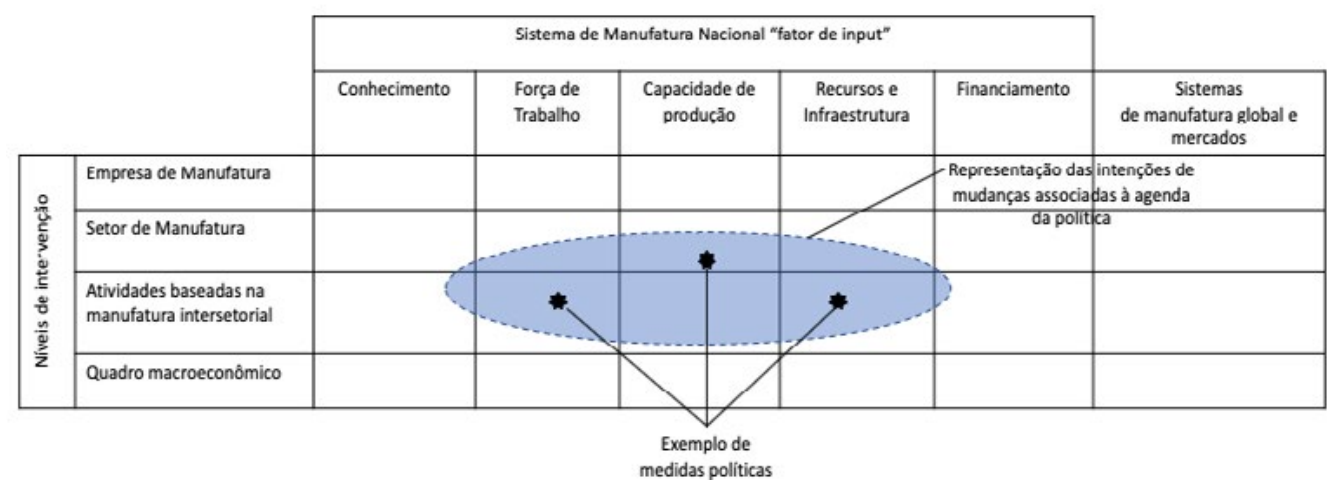

\section{5) Resultados e discussóes}

\section{Conhecimento}

Como já se sabe, a PITCE foi a principal política que colocou de volta na agenda de governo a política industrial como geradora de competitividade internacional. Antes desta política, houve alguns esforços anteriores, mas que não tiveram a mesma magnitude. Por ter sido a primeira política deste conjunto, ela foi bem incipiente em relação às políticas posteriores. Com relação ao item conhecimento, a PITCE abarcou marcos importantes 
como a Lei da Inovação, Lei do Bem e Lei da Informática, o que fomentou a geração de pesquisa e conhecimento, bem como as parcerias e o compartilhamento destes com a indústria. Ou seja, a política permitiu que institutos de pesquisa e empresas ficassem mais próximas no que tange ao desenvolvimento de tecnologia e inovação. A PDP, por sua vez, com relação à geraçáo do conhecimento, nada trouxe de novo, a não ser a institucionalização de fontes de financiamento, ampliando e sistematizando os principais resultados da PITCE.

Com relação à geração do conhecimento, o PBM foi bem mais efetivo, até porque teve outros instrumentos e agentes de apoio. O MCTI e o MEC trabalharam em conjunto com as açóes da política e, por conta da ENCTI, o ambiente inovativo foi bem mais difundido nas empresas envolvidas. Como meta da política, colocou-se também o aumento do Valor da Transformação Industrial das indústrias de alta e média-alta tecnologia, o que, juntamente com as metas da ENCTI de dar suporte às inovaçóes do setor produtivo com o intuito de se reduzir a brecha tecnológica em relação aos países desenvolvidos, evidencia que a criação e o desenvolvimento de conhecimento passaram a ser peça-chave para o ganho de competitividade (ARAÚJO, 2012; CASTELLI, 2017).

\section{Força de Trabalho}

Apesar de utilizar instrumentos voltados ao ambiente acadêmico, como a Lei da Inovação, a PITCE não conseguiu alocar esforços para fomentar a formação de recursos humanos e nem a qualificação dos trabalhadores. Existiu, no denominado PACTI (Plano de Ação para a Ciência, Tecnologia e Inovaçáo), o objetivo de aumentar as bolsas de estudo principalmente para estudantes das áreas de engenharia ligadas às áreas prioritárias da PITCE. Apesar de representar o início dos investimentos em educação, o esforço desta política não passou disso, sem trazer resultados expressivos. A excessiva ênfase na geração de conhecimento científico foi descolada do modo de produção industrial, o que gerou grandes críticas da política pelos especialistas (DIAS, 2012).

A PDP foi a primeira política que colocou em seu eixo de ação a formação e o aprimoramento de recursos humanos para embasar o caráter sistêmico de uma parte da política. Porém, apesar de alvo das açôes, ainda pouco se fez para a educação e qualificação como instrumentos de política industrial, tecnológica e de inovação durante o período vigente da PDP. Vale ressaltar que alguns esforços para a ampliação da educação no ensino superior foram feitos durante a vigência das duas políticas, como o Prouni e o REUNI, mas que não foram políticas propriamente de desenvolvimento industrial. Ou seja, na questão da educação e da qualificação de mão de obra, as duas políticas não apresentaram ferramentas suficientes, deixando de lado um dos pilares da formação de um Sistema Nacional de Inovação.

O PBM foi, dentre os três estudados, aquele que mais dispendeu esforços para a educação e a qualificação da mão de obra. Dentre as suas metas, a Plano estabeleceria que ao menos $65 \%$ dos trabalhadores da indústria deveriam ter pelo menos o nível médio completo de ensino, juntamente com a elevação da participação da indústria do conhecimento no PIB industrial. 
Com o foco em construir uma política de inovação mais sistêmica, o Plano juntamente com a ENCTI estabeleceu instrumentos para a melhoria dos recursos humanos ligados à inovação tecnológica, através de treinamento e qualificação destes, gerando "uma revolução do sistema educacional e a incorporação sistemática ao processo produtivo da inovação como mecanismo de reproduçáo e ampliação do potencial social e econômico do país" (BRASIL, 2012; CASTELLI, 2017).

Para a qualificação da mão de obra foi criado o Pronatec, cujo objetivo era ampliar a oferta de cursos de educação profissional e tecnológica por meio de ações de assistência técnica e financeira. Os alvos eram estudantes da rede pública de nível médio, incluindo a educaçáo de jovens e adultos, trabalhadores e beneficiários dos programas federais de transferência de renda.

O Ciência Sem Fronteiras foi um programa que objetivou a formação de mão de obra altamente qualificada para a formaçáo da sociedade do conhecimento, cedendo bolsas de pesquisa para estudantes de graduação e pós-graduação, das áreas estratégicas elencadas pelo PBM, para que estes estudantes tivessem contato com centros de pesquisa de excelência, e auxiliasse na ampliação do conhecimento inovador das indústrias tecnológicas em seu retorno ao país.

\section{Capacidade de Produçáo}

Este fator de entrada diz respeito a programas de apoio à produção, incentivos a PMEs, melhorias na produção, modernização do ambiente produtivo e até assistência à exportação, que podem ser fornecidos por vários agentes e instrumentos diferentes dentro das políticas industriais. Neste sentido, a PITCE, utilizando a Lei da Inovação como instrumento, criou a possibilidade de compras tecnológicas por parte do Estado com menor burocracia, o que fomenta e incentiva as empresas a produzirem produtos mais tecnológicos. As empresas também foram incentivadas a concorrer através da melhoria de técnicas produtivas que poderiam trazer reduçáo do custo e alta qualidade.

A PITCE reconhecia o problema de déficit sobre a balança comercial brasileira de produtos de alta intensidade tecnológica, mas foi a PDP que utilizou instrumentos para atingir a meta de ampliar esta categoria na pauta de exportaçóes brasileiras. Muito mais quantificável que a política anterior, a PDP colocou como objetivo a ampliação da taxa de investimento fixo de 17,4\% do PIB em 2007 para 21\% em 2010, além de dinamizar as pequenas e médias empresas, tentando colocá-las como $10 \%$ do total das empresas exportadoras do país (CASTELLI, 2017).

No caso do PBM, os esforços para pequenas e médias empresas e incentivos para compras e modernização de equipamentos foram os mesmos das políticas anteriores, não trazendo novidades nos instrumentos de política neste sentido, deixando claro que, até no PBM, a ênfase de absorção tecnológica ainda era voltada para incorporação de bens de capital e náo para o desenvolvimento próprio (CASTELLI, 2017). 


\section{Recursos e Infraestrutura}

A PITCE buscou associar as áreas prioritárias aos planos de investimento em infraestrutura (principalmente energia, logística e saneamento), a ser realizado, principalmente, por empresas, privadas e públicas, com financiamento, em grande parte, pelo BNDES.

A PDP criou uma categoria intitulada "programas para fortalecer a competitividade", voltada para setores com potencial exportador ou que gerassem efeitos de encadeamento (para frente ou para trás) na estrutura produtiva brasileira (CASTELLI, 2017). Das 420 medidas tomadas dentro da PDP, $41 \%$ delas eram relacionadas a investimentos e $29 \%$ às exportaçóes.

Em uma de suas dimensóes de política, o PBM colocava como essencial que as empresas buscassem formas de produção sustentável e integração da cadeia de suprimentos da energia, um dos principais gargalos de infraestrutura brasileiro. A exploração do présal e o desenvolvimento de tecnologias para tal fim também colocou as fontes de energia na agenda da política. O setor do agronegócio também foi bem assistido pela política, tendo como justificativa o papel das exportações de commodities no mercado internacional e a difusão da economia do conhecimento natural, associado a áreas do conhecimento estratégicas como a biotecnologia.

\section{Financiamento}

O BNDES foi o principal agente de financiamento da política industrial brasileira recente. Mais do que isso, Toni (2015) afirma que, além de financiar, o Banco atuou no apoio à formulação e como agente de implementação dos instrumentos de política.

$\mathrm{Na}$ PDP, que coincidiu com a crise financeira internacional, o BNDES expande a sua escala de operaçóes, guardando relação com a evolução do investimento na economia.

O PBM foi o que mais utilizou o BNDES como instrumento de política industrial. Dentre as medidas utilizadas, destacam-se a ampliação das linhas de financiamento do BNDES, substituiçôes tributárias - para segmentos selecionados - e a redução de impostos indiretos, como o IPI (Imposto sobre Produtos Industrializados) (CASTELLI, 2017). Além disso, outros órgãos, como a FINEP, auxiliaram a articulação do Plano na aproximação das empresas nacionais com a academia e os centros de pesquisa, principalmente com o crédito, subvenção e poder de compra do Estado.

\section{Níveis de intervenção da política}

Todas as políticas apresentadas atuaram de certo modo com o nível setorial da indústria. No caso da PDP, os setores estratégicos passam por uma quantidade bem maior que a PITCE, o que posteriormente foi detectado como um entrave para o andamento da política pela falta de coordenação e direcionamento, uma vez que, quando a priorização setorial começa a ser ampla, isto indica que na verdade não há a percepção de que algum setor seja realmente prioritário a ponto de permitir o efeito transbordamento para os demais setores e nem gerar desenvolvimento industrial. Já no caso do PBM, foi elencado um 
conjunto de políticas tanto setoriais quanto sistêmicas, sempre com a preocupação de aliar ferramentas macroeconômicas com o desempenho inovativo industrial.

Diante dos resultados apresentados, segue a construção das matrizes de política industrial evidenciando as principais diferenças de atuação entre elas, principalmente no nível de intervenção e nos objetivos que seus instrumentos eram focados.

Figura 2: Matrizes de política industrial para as experiências brasileiras. Elaborado pelo autor a partir da análise do trabalho (2019).

PITCE

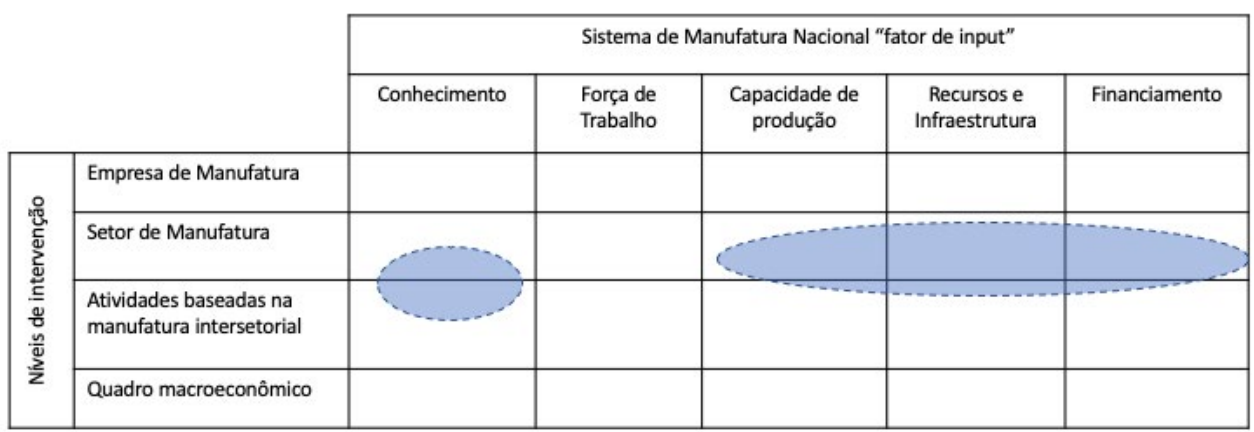

PDP

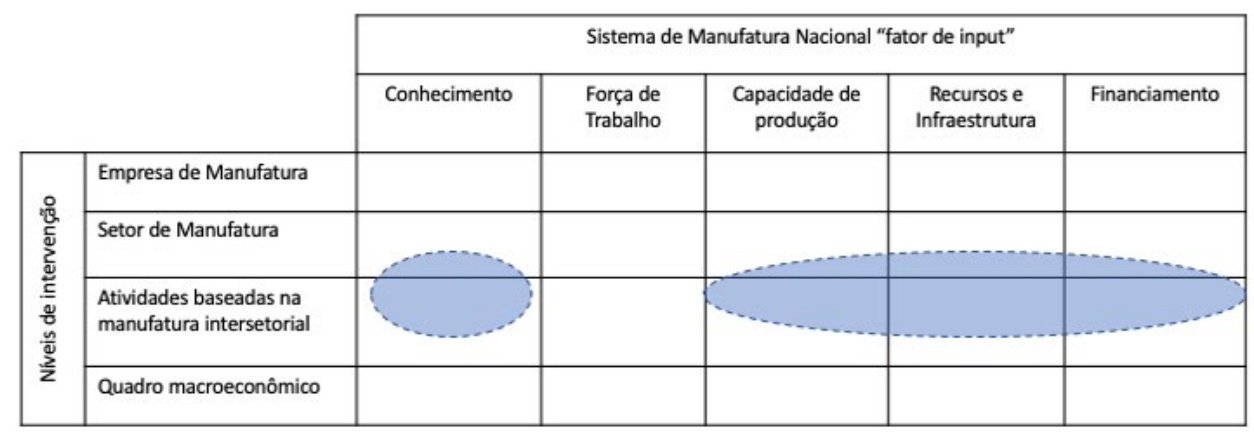

PBM

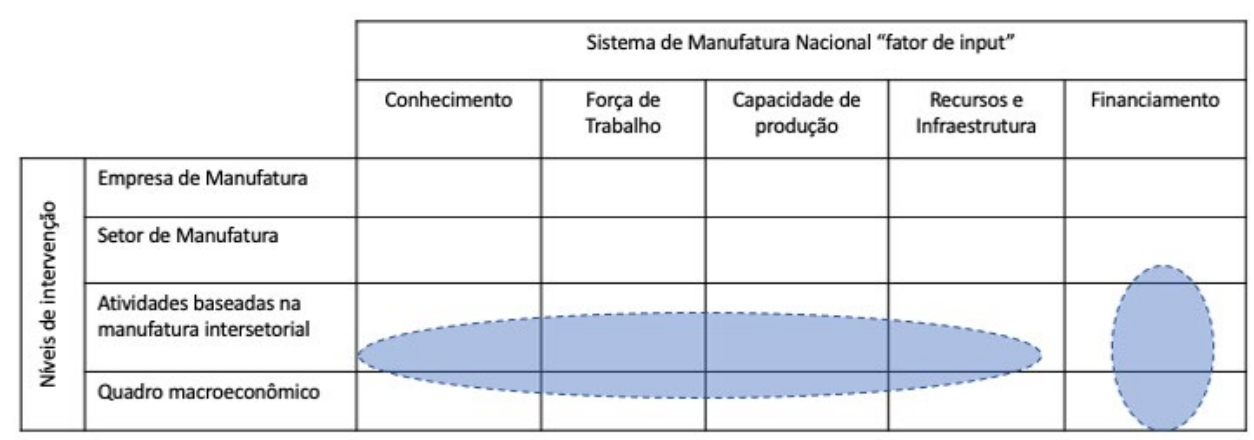


Nota-se que o esforço de educação e força de trabalho só foi contemplado pelo PBM, o que aumentou ainda mais o atraso brasileiro com relaçáo a formação de mão de obra qualificada. Percebe-se que houve uma evolução do nível de intervenção das políticas no sentido de integrar os setores. Essa constatação está de acordo com os estudos sobre Sistemas Nacionais de Inovação e demonstram que as políticas industriais estimularam a interaçáo entre os agentes econômicos para a criação de um ambiente inovativo.

Apesar de as políticas apresentarem uma evolução no caminho de alinhar as políticas industrial e macroeconômica, há diversos estudos, tais como Erber (2011), que mostram que este alinhamento de fato não ocorreu, existindo conjuntamente duas "convenções de desenvolvimento", uma mais desenvolvimentista ligada às políticas industriais e outra mais institucionalista neoclássica mais próxima das política macroeconômicas.

Vale ressaltar também que, mesmo existindo financiamento como fator de entrada na PITCE e PDP, foi no PBM que este instrumento ganhou força, principalmente representado pelo BNDES, que, além de atuar como instrumento de financiamento, participou ativamente da elaboração e implementação de programas alinhados com a política industrial vigente.

Contudo, posterior ao PBM, novamente a política industrial deixou de estar presente na agenda de governo. Mesmo que elogiado pela CEPAL (2018) pela iniciativa por ter permitido a manutenção de uma agenda de política industrial num cenário de fortes restriçôes fiscais, o Brasil Mais Produtivo foi um esforço muito tímido de política industrial que visava elevar a produtividade de processos produtivos, com a promoçáo de melhorias rápidas, de baixo custo e alto impacto, com foco nas pequenas e médias empresas brasileiras. O programa atingiu os objetivos aos quais se propunha, mas ficou longe de ser uma política industrial por não possuir um caráter sistêmico, já que atingiu três mil empresas industriais, deixando de lado o desenvolvimento tecnológico e a inovação no processo produtivo.

\section{6) Consideraçóes Finais}

O trabalhou buscou ilustrar e comparar três esforços de política industrial brasileiro (PITCE, PDP e PBM) com relação aos níveis de intervenção e fatores socioeconômicos atingidos, por meio do uso da ferramenta de análise criada por O'Sullivan et al. (2013) denominada de Matriz de Política Industrial que permitiu sintetizar os principais instrumentos das políticas estudadas.

A análise identificou que, a partir da implementação da PITCE, a política industrial foi incluída mais ativamente na agenda de governo. Percebe-se também que as três políticas atuaram como evolutivas, com a PDP e o PBM tentando melhorar e corrigir os erros de suas políticas antecessoras. $\mathrm{O}$ nível de intervenção da política também evoluiu, deixando de ser setorial na PITCE até atingir o nível de associação com o ambiente macroeconômico como o caso do PBM.

A PITCE atuou no fomento de setores e bases de conhecimento estratégicos para o desenvolvimento econômico. A PDP ampliou a gama de setores estratégicos e o PBM consolidou uma série de setores divididos em três grandes grupos de atuação. Apesar da 
Lei da Inovação ter sido um instrumento legal criado na vigência da PITCE, foi a PDP e o PBM que mais auxiliaram no processo de formação de um Sistema Nacional de Inovação.

É enfatizado também, conforme constatado por Castelli (2017), que, em momentos de crise e de restrição fiscal, a política industrial é a primeira a sair da agenda de governo, como no caso do fim do PBM. Isso mostra que talvez seja este o problema de os ciclos de política industrial não durarem muito historicamente. Essa afirmação é corroborada pelo contexto econômico brasileiro atual, onde, após o PBM, houve apenas um pequeno esforço de política industrial, o chamado Brasil Mais Produtivo. Atualmente, a política industrial está fora da agenda de governo, o que pode comprometer todos os ganhos auferidos pelas políticas anteriores.

Entre os agentes de política industrial, o BNDES exerceu um papel fundamental dentro das três políticas, aumentando sua importância no decorrer do tempo, passando de mero financiador na PITCE para agente de formulação, implementação e controle no PBM.

O trabalho se limitou em analisar o tamanho da intervenção do Estado no processo de implementação de política industrial. Informações sobre o contexto político econômico internacional não foram incluídos na análise. Dados sobre o desempenho industrial neste processo também poderiam ser apresentados e analisados.

O trabalho foi capaz de apontar uma progressão na convergência entre as políticas industriais e a política macroeconômica, principalmente no início da implementaçáo do PBM. Porém, houve uma limitaçáo pela metodologia adotada em se detectar o grau de interlocuçáo entre as políticas industriais e as políticas macroeconômicas. Uma política nacional de desenvolvimento exige que ambas as políticas sejam implementadas complementar e concomitantemente, o que segundo Erber (2011) não chegou a acontecer no país nas políticas recentes. Ou seja, houve melhoras na convergência das políticas industriais e macroeconômicas, mas não a ponto de se configurarem como políticas nacionais de desenvolvimento.

Diante disso, sugere-se, para trabalhos futuros, uma análise sobre a influência das convençóes de desenvolvimento da política econômica internacional sobre a tomada de decisão dos policemakers, no intuito de encontrar convergências entre açóes de política industrial e políticas macroeconômicas em prol do desenvolvimento socioeconômico do país. Sugere-se também alguns trabalhos empíricos sobre o desempenho industrial resultante dos principais instrumentos de política industrial utilizados, tais como financiamentos do BNDES e FINEP, benefícios fiscais e estímulo a cooperação entre empresas e institutos de pesquisa.

\section{Referências}

AGHION, P.; BOULANGER, J.; COHEN, E. Rethinking Industrial Policy. Bruegel Policy Brief, n. 04, 2011.

ALMEIDA, J. G. Alcances e lacunas da nova política industrial. Campinas: [s.n.]. 
ANDREONI, A.; CHANG, H. J. The political economy of industrial policy: Structural interdependencies, policy alignment and conflict management. Structural Change and Economic Dynamics, 2018.

ARAÚJO, B. C. Políticas de Apoio à Inovação no Brasil: uma análise da evoluçáo recente. Textos para discussão. IPEA/Rio de Janeiro, 2012.

AVELLAR, A. P. M.; BOTELHO, M. R. Impacto das Políticas de Inovaçáo nas Pequenas, Médias e Grandes Empresas BrasileirasXLII Encontro Nacional de Economia da ANPEC. Anais...2016

BARBOSA, T. C.; BAGATTOLLI, C.; INVERNIZZI, N. Política de inovação em nanotecnologia no Brasil : a trajetória dos instrumentos financeiros não reembolsáveis. p. 56-74, 2018.

BIELSCHOWSKY, R. ESTRATÉGIA DE DESENVOLVIMENTO E AS TRÊS FRENTES DE EXPANSÃO NO BRASIL: UM DESENHO CONCEITUAL. In: CALIXTRE, A. B.; BIANCARELli, A. M.; CINTRA, M. A. M. (Eds.). . Presente e Futuro do desenvolvimento brasileiro. Brasília: [s.n.]. p. 643.

CALZOLAIO, A. Política Industrial e Produtividade na Indústria de Transformação do Brasil na Década de 2000. Tese de Doutorado. Universidade Federal de Rio Grande do Sul, 2015.

CANO, W.; SILVA, A. L. G. DA. Política Industrial do governo Lula. Textos para discussão IE/Unicamp, n. 181, 2010.

CASSIOLATO, J. E.; SZAPIRO, M.; VARGAS, M. A. Avanços e limitaçóes da política de inovação brasileira na última década: Uma análise exploratória. Espacios, v. 37, n. 5, p. $18,2016$.

CASTELLI, J. R. A trajetória dependente da política de inovação brasileira (19952012): Hábitos de pensamento e enraizamento institucional. [s.l.] Universidade Federal do Rio Grande do Sul, 2017.

CHANG, H. J. The Political Economy of Industrial Policy. New York: St. Martin's Press, INC, 1994.

CHIARINI, T.; VIEIRA, K. P. Alinhamento das atividades de pesquisa científica e tecnológica realizadas pelas IES federais de Minas Gerais e as diretrizes da Política Industrial, Tecnológica e de Comércio Exterior - PITCE. RBI-Revista Brasileira de Inovação, v. 10, n. 2, p. 301-342, 2011.

CIMOLI, M. et al. Instituições e Políticas Moldando o Desenvolvimento Industrial : uma nota introdutória. Revista Brasileira de Inovação, v. 6, n. 1, p. 55-85, 2007. 
COSTA, A. C. Política de inovaçáo brasileira: análise dos novos instrumentos operados pela Finep. Tese de Doutorado. IE/UFRJ, 2013.

ERBER, F. S. Innovation and the Development Convention in Brazil. Revista Brasileira de Inovaçáo, v. 3, n. 1, 2004.

ERBER, F. S. As convençóes de desenvolvimento no governo Lula: um ensaio de economia política. Revista de Economia Política, v. 31, n. 1, p. 31-55, 2011.

FERRAZ, J. C.; MARQUES, F. S.; ALVES JR, A. J. A contribuição do BNDES para a política industrial brasileira 2003-2014. In: Dez anos de política industrial: balanços e perspectivas. Brasilia: ABDI, 2015. .

HAQUE, I. UL. Rethinking Industrial Policy. In: International Development Governance. [s.1.] Routledge, 2017. p. 685-700.

JOHNSON, C. The Industrial Policy Debate. San Francisco: Institute of Contemporary Studies, 1984.

LAPLANE, M. F. A indústria ainda é o motor do crescimento? In: Dez anos de política industrial: balanços e perspectivas. Brasília: ABDI, 2015. p. 23-40.

NELSON, R. R. Reflections of David Teece's "Profiting from technological innovation...”. Research Policy, v. 35, n. 8, p. 1107-1109, 2006.

O'SULLIVAN, E. et al. What is new in the new industrial policy? A manufacturing systems perspective. Oxford Review of Economic Policy, v. 29, n. 2, p. 432-462, 2013.

PAVITT, K. Sectorial patterns of techinical change: towards a taxonomy and theory. Research Policy, v. 6, n. 13, p. 343-373, 1984.

SALERNO, M. S. A política industiral, tecnológica e de comércio exterior do governo federal. Parcerias Estratégicas, v. 9, n. 19, p. 23, 2004.

SARTI, F; HIRATUKA, C. Transformações na estrutura produtiva global , desindustrialização e desenvolvimento industrial no Brasil : uma contribuição ao debate.

Textos para Discussão IE/Unicamp, n. 290, 2015.

SCHAPIRO, M. G. Ativismo estatal e industrialismo defensivo: intrumentos e capacidades na política industrial brasileira. Textos para discussão IPEA/Brasília, n.1856, 2013.

SUZIGAN, W.; VILELLA, A. Industrial Policy in Brazil. Campinas: Editora Unicamp, 1997. 
TAVARES, M. DA C. Auge e declínio do processo de substituição de importaçōes. In: Cinquenta anos de pensamento da CEPAL2. Rio de Janeiro: Record/CEPAL, 2000. .

VILELLA, A. Dos anos dourados de JK à crise não resolvida. In: Economia Brasileira contemporânea. São Paulo: Campus, 2005. 